\title{
Keeping the public under the microscope
}

\author{
New research confirms that the proportion of the public that knows about nanotechnology has \\ reached a plateau, which means that it is now necessary to develop new approaches to explore public \\ perceptions in greater detail than before.
}

In recent years, authors in this journal and elsewhere have frequently expressed the fear that nanotechnology might become the next GM, and stressed the need for the nanoscience and technology community to engage with the public and be open about the results of their research and the products that they are developing. A failure to do so, they feared, would lead to public opposition similar to that experienced by the nuclear industry and companies selling genetically modified food. The nano community has responded to these calls with a welter of public engagement activities, surveys, codes of practice and other activities.

It will never, of course, be possible to say that all these fears have been allayed and all these activities can be ramped down. What needs to happen is that existing policies for regulating new chemicals, materials and products are updated and extended to cover new nanomaterials and nano-enabled products, and that the bodies responsible for food safety, the approval of new medicines, protection of the environment, health and safety in the workplace and so on enforce these regulations in a way that protects people and the environment while - and this is the tricky bit that no one has resolved yet - allowing responsible research and innovation to flourish.

\section{Could it be that synthetic biology wants to become the 'next nano'?}

The nanoscience and technology community should also continue to engage with the public, especially as research into public attitudes towards nanotechnology becomes more detailed and sophisticated, probing deeper into the ways in which different subgroups of the public react to nanotechnology. There are signs that research into these aspects of nanotechnology are moving from an initial experimental phase into a more mature and focused phase. Indeed, the results of the latest annual survey of US adults carried out by Hart Research Associates for the Project on Emerging Nanotechnologies at the Wilson Center are mostly concerned with synthetic biology rather than nanotechnology ${ }^{1}$. Given that nano seems to have (so far) avoided becoming the next GM, could it be that synthetic biology wants to become the 'next nano'?

The Hart surveys have been performed every year since 2006 and the latest survey confirms that there have been "only minor shifts" in awareness of nanotechnology over the past four years: $31 \%$ of respondents say they have heard a lot or some about nano (compared with 30\% in 2004), whereas $68 \%$ have heard little or nothing (compared with 69\%). Men under the age of 50, college graduates and people earning more than $\$ 75,000$ per year are the subgroups most likely to have heard about nanotechnology.

Another sign of the maturity of research in this field is the publication of the first meta-analysis of survey data on public attitudes towards the risks and benefits associated with nanotechnology (see page 752 of this issue). Terre Satterfield and colleagues looked at 22 publications reporting the results of surveys and found that the public response to nanotechnology has, so far, been different to the responses to previous new technologies in a number of ways. In particular, and contrary to expectations, unfamiliarity with nanotechnology is not strongly associated with risk aversion. The meta-analysis also reveals that twice as many people think that the benefits will outweigh risks as vice versa, but the authors caution that "a large minority of those surveyed (44\%) is unsure, suggesting that risk judgments are highly malleable." Satterfield and colleagues also call for the development of new methods to understand public responses to nanotechnologies. In an accompanying News \& Views on page 705 Dan Kahan concludes that "the metaanalysis suggests that public attitudes toward nanotechnology remain open to the guidance of sound science, but that it would be a serious error to take such receptivity for granted."

Meanwhile the DEEPEN (Deepening Ethical Engagement and Participation with Emerging Nanotechnologies) project which involved researchers from ethics, philosophy and the social and political sciences - has published a report ${ }^{2}$ that looks at the development of nanotechnology from the perspective of public policy and ethics. We will focus here on the lessons for public policy (see ref 3 . for more about nanoethics). Although the authors of the report say that current work in this field is "impressive", they also argue that this work is "still dominated by limited and limiting modes of thought", and they go on to make ten recommendations that, they say, will make "uncomfortable reading" for anyone doing research or making policy on the social and ethical aspects of nanotechnology.

\section{Unfamiliarity with nanotechnology is not strongly associated with risk aversion.}

Some of the recommendations chime with those of Satterfield and colleagues and are hard to disagree with, such as the calls to "understand the complexity of public 'attitudes"' or to question the status quo in which scientists do science and leave others to deal with the social implications (ref. 4 and reference therein). However, like many articles and reports before it, the DEEPEN report is often more comfortable pointing out the shortcomings in present practices rather than offering specific solutions to these problems and challenges.

It is important, therefore, that the nanotechnology community - researchers, funders, regulators and others - continues to work hard to ensure that nano does not become the next GM, all the time accepting that there might always be new questions to answer and new challenges to address.

\footnotetext{
References

1. Nanotechnology, Synthetic Biology and Public Opinion (Hart Research Associates, 2009); available at <http://www.nanotechproject.org/publications/archive/8286/>.

2. Reconfiguring Responsibility (DEEPEN, 2009); available at $<$ http://www.geography.dur.ac.uk/projects/deepen/Home/ tabid/1871/Default.aspx >

3. Nordmann, A. \& Rip, A. Nature Nanotech. 4, 273-274 (2009).

4. Jones, R. A. L. Nature Nanotech. 4, 336 (2009).
} 